\title{
Tecnologias Videográficas Como Dispositivos Para o Exercício da Cognição Enativa
}

\author{
Videographic technologies as devices \\ for the exercise of enactive cognition
}

\begin{abstract}
Resumo: Este trabalho visa discutir alguns efeitos da utilização de tecnologias videográficas em oficinas inseridas em uma proposta de pesquisa-intervenção, em um centro de saúde para dependentes de substâncias químicas. As redes de conversação que emergem no cotidiano da instituição, campo do estudo, não operam de modo intencional na dimensão problematizadora e criativa da cognição. Com a intenção de avaliar a possibilidade de criar outras redes de conversação que pudessem abrir brede criar outras redes de conversação que pudessem abrir brechas nas certezas instituidas, propusemos, juntamente com os usuários do centro, uma oficina intitulada oficina de máscaras que, além de uma proposição de fabricação artesanal das mes mas, acopla tecnologia videográfica em seu desenvolvimento. As oficinas ocorrem semanalmente e os usuários do centro são convidados a participar. Tomamos o conceito de cognição enativa como uma ferramenta metodológica tanto para a proposição das oficinas quanto para a análise das redes de conversação delas emergentes. Constatamos que a utilização de dispositivos videográficos nas oficinas possibilitam a emergência de diferentes linguajares e emocionares, pela instauração de outras coordenações de ações e posições subjetivas na rede coletiva. A ação de filmar a oficina e a experiência de retomar esse vídeo constituem-se num dispositivo de atualização enativa. É por essa operação de duração do tempo gerúndio, do acontecendo que podemos dizer que se desdobra aí um virtual inusitado que podemos dizer que se desdobra aí um virtual inusitado rede de conversação estabelecida institucionalmente. O vídeo não existe somente como registro da experiência, mas como desdobramento de criação, como um modo distinto de linguajar ou seja, de realizar coordenações de ações recursivas e inusitadas e não somente

Palavras-chave: Tecnologias videográficas. Redes de conversação. Cognição enativa.
\end{abstract}

Abstract: This paper aims to discuss some effects of the employment of videographic technologies in workshops inserted into an intervention research proposal, in a health care centre for dependents of chemical substances. The conversation networks that emerge in the daily life of the institution, that is our study field, do not operate in an intentional mode concerning the problematizing and creative dimension of cognition. Considering the intention of evaluating the possibility of creating other ring the intention of evaluating the possibility of creating othe conversation networks that could leave no room for instituted certainties, we proposed, in conjunction with the users of the centre, a workshop entitled masks workshop, which proposes a handmade activity together with videographic technology in its development. The workshops occur weekly and the users of the centre are invited to participate. We take the concept of enac tive cognition as methodological tool concerning the proposal of workshops, and the analysis of conversation networks which emerge from such activity. We note that the employment of videographic devices in the workshops enable the emergency of different uses of language and emotions through the establishment of other coordination of actions and subjective positions in the collective network. The action of filming the workshop and the experience of looking such video over again constitutes device of enactive updating. It is through such operation, which takes place on the gerund tense "happening", that one can state takes place that an unusual virtual is unfolded to the conversation network rablished institutionally. The video does not just exist just regards the experience, but also as an unfolding of the creation, as a distinct manner of language, that is, a distinct manner of accomplishing the coordination of recursive and unusual actions that goes beyond consensuality.

Keywords: Videographic technologies. Conversation networks. Enactive cognition

LOPES, Graziela Pereira; MARASCHIN, Cleci. Tecnologias Videográficas Como Dispositivos Para o Exercício da Cognição Enativa. Informática na Educação: teoria \& prática, Porto Alegre, v. 12, n. 2, p. 123-131, jul./dez. 2009.

\author{
Graziela Pereira Lopes \\ Mestre em Psicologia Social e Institucional (UFRGS) \\ Cleci Maraschin \\ Universidade Federal do Rio Grande do Sul
}

\section{I ntrodução}

5 ste trabalho visa discutir a prática de oficinas que disponibilizam tecnologias videográficas no campo da saúde mental a partir de uma proposta de pesquisa-intervenção em um centro de saúde para dependentes de substâncias químicas. Embora a modalidade oficina seja uma prática bastante utilizada nos serviços de saúde mental, principalmente naqueles que se propõem a ser substitutivos da internação ${ }^{1}$, oficinas que utilizam ferramentas das Tecnologias da I nformação e Comunicação (TIC) são ainda recentes e pouco numerosas.

Experiências desenvolvidas por outros pesquisadores $^{2}$ no campo da saúde mental evidenciam que as TICs favorecem à produção autoral (de vídeos, músicas, textos, hiperdocumetos, fotos, dependendo do foco da oficina)

1 Trabalhos desenvolvidos por Ana Cristina Costa de Figueiredo, Andréa Máris Campos Guerra, Clarisse Moura Costa, dentre outros. Ver: Costa e Figueiredo, 2004.

2 CAPELLA, N.; MARASCHIN, C.; MAURENTE, V.S.; RICKES, S., 2009; DIEHL, R.; MARASCHIN, C.; TITTONI, J., 2009 ; FRANCISCO, D.J.; MARASCHIN, C.; AXT, M., 2007; RAINONE, F.N.; FROEMMING, L.S., 2008; A dissertação de mestrado de Vianna, T.R., 2008; SANTORUM, K. 2006. 
considerando, ao mesmo tempo, a inserção na rede de conversação que emerge das oficinas e a posição de singularidade (diferença) nessa mesma rede. Nomeamos de posição de autoria essa dupla condição: proposição singular aceita e reconhecida na e pela rede de conversação da qual emerge. Cabe aclararmos que tomamos a idéia de redes de conversação a partir de Maturana (2001), que as define como um fluir no linguajar e no emocionar, conforme explicitamos adiante.

Uma das autoras desse texto conhece e trabalha há seis anos na instituição onde a oficina foi desenvolvida. A partir dessa experiência, avalia que, nas redes de conversação - entre trabalhadores, internos e familiares - existentes no cotidiano da instituição, predominam algumas concepções, tais como: dependência química é doença; o controle da dependência depende do conhecimento da doença; conhecimento é informação. Combinado a essas relações, cultiva-se um emocionar que faz com que cada usuário do centro se admita doente, causador de danos a si e aos que com ele convivem e aceite internalizar as modalidades de controle oferecidas. Uma rede de conversação assim instituída é fundada em uma cognição representacional, na qual se passa a acreditar que a recuperação só é possível pela tomada de consciência advinda dos ensinamentos prestados por profissionais da instituição sobre o que é a doença dependência química e pelo desenvolvimento de controles internos de enfrentamento. Segue a lógica de que o interno, quanto mais souber sobre sua doença, mais terá condições de lidar com ela. Limita a experiência a um processo de acesso a determinadas informações e de mecanismos de evitação e de solução de problemas, sem espaço para a problematização, para uma reapropriação ativa, enativa da questão.

Com a intenção de avaliar a possibilidade de produzir deslocamentos nas redes de conversação que pudessem questionar as certezas instituídas, colocando os participantes em uma posição de autoria, foi proposta, juntamente com os usuários do centro, uma oficina intitulada oficina de máscaras. A oficina, além de uma proposição de confecção artesanal de máscaras, acopla tecnologia videográfica em seu desenvolvimento. Temos, neste artigo, o intuito de, ao apresentarmos a experiência produzida nas oficinas pelo uso do vídeo, discutir as redes de conversação que emergem da experiência e o quanto ela potencializa, ou não, esses deslocamentos.

\section{Cognições}

Existem diferentes perspectivas teóricas através das quais se estuda e se trabalha com a cognição no campo da saúde. Cabe explicitarmos que a perspectiva, neste estudo, encara a cognição como resultante de redes de conversação que emergem na interseção entre as contingências biológicas, institucionais e tecnológicas. Esse modo de pensar a cognição só pode ser analisado a partir da perspectiva da ecologia cognitiva que a constitui. Para Lévy (1993), a ecologia cognitiva busca estudar a cognição considerando suas dimensões singulares, técnicas e institucionais.

A perspectiva da ecologia cognitiva implica que a cognição não possa ser considerada como a representação de um mundo independente de nossa corporeidade, de nossas técnicas e de nossa cultura. A cognição resulta desses acoplamentos, tendo um componente autoprodutivo, autopoiético (MATURANA; VARELA, 2001). Advém daquilo que fazemos e do modo como operamos, com as ecologias cognitivas que nos cabem viver. Ela é relação, ação, conexão (AXT; MARASCHIN, 1998).

Por seu caráter auto e heteroprodutivo, compreendemos a cognição como produção de si e de mundos (KASTRUP, 1999) e não, como já salientamos, pela via da representação de uma realidade que existe independentemente dos sujeitos em seus coletivos de conversação. Desse modo, se retomamos as redes de conversação, predominantes no serviço em foco, podemos dizer que elas operam na construção de sujeitos e de mundos vivíveis com suas práticas e tecnologias próprias.

A noção de cognição como ação corporificada - enação (VARELA; THOMPSON; ROSCH, 2003) - liga-se à idéia de ecologia cognitiva, ao possibilitar tomar as capacidades cognitivas como corporificações decorrentes das histórias que são vividas, ou seja, atuação ou produção de um mundo através de uma história de acoplamento estrutural (aos outros, às instituições e às tecnologias). As competências ou capacidades cognitivas não são, assim, modelos abstratos de relações simbólicas que operam independentemente das experiências vividas e de suas materialidades. O modo operativo atual de um sujeito, que é produto recursivo do 
acoplamento com sua circunstância, é o que determina quais mudanças ocorrerão no mesmo com os encontros advindos da experiência. Dessa forma, a interação nunca é diretamente instrutiva, porque não é unicamente da ordem de uma transmissão ou de um processamento informacional.

Embora possa parecer um paradoxo a proposição de uma intervenção que busque não somente resolver problemas, mas problematizar no contexto de um serviço de saúde mental apostamos, que a possibilidade de exercícios de autoria pode trazer um diferencial na posição em que cada um se coloca diante das questões existenciais que os trazem ao serviço. Apesar de alguns modelos de intervenção em saúde baseados prioritariamente na transmissão de informações parecerem funcionais, os mesmos não são instrutivos por si só, ou seja, não determinam o que vai acontecer com os sujeitos. O que lhes acontecerá é determinado por suas estruturas, isto é, pelo modo com que viveram, pela história dos distintos acoplamentos realizados e pelas redes de conversação das quais participam. Cabe pensarmos, então, o quanto o sucesso desses modelos é dependente de uma estrutura heterônoma e autocontroladora.

Tomamos o conceito de cognição enativa como uma ferramenta metodológica que nos potencializa distinguir momentos em uma rede de produção-conversação nos quais exista um linguajar que vitalize coordenações de ações até então inusitadas na história desse coletivo e um emocionar em que a experiência do outro possa ser aceita como legítima. A cognição enativa consiste não na constituição de modelos sobre o mundo, mas na capacidade de propor, dentro de limites muito amplos, as questões relevantes que precisam ser focadas, em cada momento, no contexto da rede de conversação na qual se dão. Essas questões e preocupações não são preestabelecidas, mas atuadas a partir de um pano de fundo de ação onde o que conta como relevante é contextualmente determinado pelo senso comum, que nada mais é que nossa história corpórea e social do coletivo que compartilhamos (VARELA; THOMPSON; ROSCH, 2003).

Assim, antes de buscarmos um modelo de intervenção que resolvesse os problemas causados pelo uso abusivo de substâncias químicas, optamos por construir condições nas quais fosse valorizado o exercício enativo. A aposta era a de sermos capazes de produzir outras redes de conversação, que tornassem possível aos sujeitos a emergência de questões pertinentes a si mesmos e aos mundos que constroem coletivamente, em uma atitude autoprodutiva e não somente adaptativa, onde possam enatuar coletivamente outras possibilidades de existência.

Nessa perspectiva, as redes de conversação apresentam-se como uma espécie de espaço de agenciamento ontológico do viver como humanos, nas quais são geradas ou extinguidas modalidades de ser, de pensar e de sentir. Segundo Maturana (2001), como humanos, existimos na linguagem, no fluir de nossas conversações, de modo que todas as nossas atividades acontecem e constituem diferentes domínios de conversações. Conseqüentemente, nossos domínios diversos de ações (domínios cognitivos) são formados por diferentes redes de conversações. Para o autor, a conversação é uma operação no fluxo entrelaçado de coordenações consensuais de linguajar e emocionar, e conversações são as diferentes redes de coordenações entrelaçadas e consensuais de linguajar e emocionar que geramos ao vivermos juntos. Nesse plano, uma cultura pode ser pensada como a recursiva ativação de uma rede de conversações que define um modo de viver.

Outra aposta é que as redes de conversações possam fazer emergir não só sujeitos, mas coletivos. Interessa também mapearmos o que Lévy (1998) chamou de coletivo inteligente, coletivo ${ }^{3}$ este que não submete, nem limita, as inteligências individuais, pelo contrário, abre-lhes novas potências. O intelectual coletivo pensa em toda parte, o tempo todo, e retoma perpetuamente o pensamento de seus membros, de modo que ele é acelerado pela técnica, pela linguagem e pelo pensamento, aumentando sua capacidade de reorganização, reduzindo seus prazos de inovação e multiplicando seu potencial inventivo. No entanto, essa velocidade cognitiva só será atingida quando mobilizar as subjetividades singulares que o compõem.

3 Mistura de homens e coisas que se auto-organizam, mantendo-se e transformando-se através do envolvimento permanente dos indivíduos e das tecnologias que a compõem. É dinâmico, aberto, percorrido de individuações auto-organizadoras, locais, e pontuado por singularidades mutantes (LÉVY, 1993). 


\section{Luz, Câmera Cogni(a)ção: as oficinas}

As oficinas de máscaras ${ }^{4}$ iniciaram, em juIho de 2008, como um convite para os internos que desejassem participar. Devido ao tempo de permanência deles na instituição, que varia de 28 a 35 dias, houve bastante alternância de participantes. Delas participaram homens e mulheres com idade entre 18 e 70 anos. Cada uma tinha um limite de 15 pessoas.

As oficinas tinham periodicidade semanal e eram desenvolvidas em duas etapas: a primeira (com duração de uma hora e quarenta e cinco minutos) consistia na oficina de construção e performance das máscaras, que era filmada e/ou fotografada pela proponente ou pelos participantes; a segunda (com duração de quarenta e cinco minutos), na fruição dos registros da oficina (fotos e/ou vídeos). A primeira etapa era constituída por vários momentos: a construção da máscara, que leva à criação de um personagem, o qual adquire uma história durante o processo de montagem, e, por fim, a apresentação oral e corporal do mesmo. A apresentação corporal dava-se através de um desempenho (pose, movimento, individual ou grupal) que caracterizava a máscara, ou melhor, o personagem inventado, atuado. Durante toda a atividade, a filmadora ficava disponível para quem desejasse filmar. A segunda etapa ocorria na semana seguinte, quando, então, as fotos ou o vídeo produzido eram disponibilizados ao coletivo. O material não era editado. A visibilidade trazida pelas fotos e pelo vídeo foi ganhando importância. Devido às combinações estabelecidas no próprio termo de consentimento, para que qualquer pessoa que não tivesse participado da oficina pudesse assistir aos registros da atividade era preciso a autorização do grupo. Isso colocava os participantes em uma posição diferenciada daquela que geralmente assumiam. Comentando a situação, diziam que: Ao menos isso é a gente que decide aqui dentro, não vejo problema nenhum os colegas assistirem, mas acho legal eles perguntar nossa opinião, ao menos respeitam o nosso acordo. Esse material é de pesquisa, mas é, antes de tudo, a

4 Totalizando 24 oficinas (com essa configuração de vídeo + máscaras) até dezembro de 2008. produção de um coletivo ${ }^{5}$.

O uso de câmeras fotográficas e de vídeo na oficina deu-se por influência do grupo de pesquisa ${ }^{6}$, através de leituras e discussões sobre o tema no campo da saúde mental. Com o desenrolar dos estudos e a verificação dos efeitos potencializadores que a tecnologia possibilitava decidimos incluir o uso da filmadora na oficina. Assim, tal inserção na pesquisa surgiu como um dispositivo que, além de ampliar as possibilidades das conversas, também as configurava. Trata-se de uma nova experiência, que ao retomar a experiência anterior, produz uma atualização do vivido, revivendo-o.

Compreendemos a operação que a tecnologia produz a partir da perspectiva da ecologia cognitiva, como salientamos no início do texto. Segundo Lévy (1993), as tecnologias agem diretamente sobre a ecologia cognitiva, na medida em que transformam a configuração da rede de conversação, produzindo outras coordenações de ação e metáforas para se pensar-com. Nas primeiras oficinas, disponibilizamos uma máquina fotográfica, que foi pouco utilizada pelos participantes e mais pela pesquisadora. As fotos eram vistas, primeiramente, na máquina, durante a própria atividade. Após algumas oficinas, conseguimos visualizar as fotos na tela da televisão. Entretanto a atividade de ver as fotos não proporcionava questionamentos ou problematizações, mas comentários. Alguns demonstravam certa decepção na transformação das cenas (ação, movimento) em imagens estáticas. Então, por sugestão dos participantes, foi disponibilizada para a atividade uma câmera de vídeo.

O uso da câmera de vídeo durante a atividade mostrou-se, desde o início, muito interessante para os propósitos da pesquisa que tinha na problematização, que emergia das redes de conversação, seu foco principal. Utilizar a filmadora, num primeiro instante, produziu um sentimento de estranhamento e desconfiança: um problema. Algumas pessoas deixaram de

5 Coletivos inteligentes: “[. . . ] recriação do vínculo social mediante trocas de saber, reconhecimento, escuta e valorização das singularidades, democracia mais direta, mais participativa, enriquecimento das vidas individuais, invenção de formas novas de cooperação aberta." (LÉVY, 1996, p. 117-118).

6 Grupo de pesquisa Políticas Públicas e Produção de Subjetividade, cuja linha de pesquisa Redes, Artefatos Simbólicos e Invenção de Si é coordenada pela Professora Cleci Maraschin da UFRGS. 
participar da atividade devido à presença da filmadora, ou melhor, com o que poderia ser produzido com ela (preocupação com quem poderia ter acesso às imagens). Esse problema de confiança foi discutido coletivamente, e uma série de combinações foram acordadas, como no exemplo do acesso às imagens comentado acima.

Quanto ao contato com a filmadora, alguns evitavam a princípio, por medo de estragar; outros, por medo do objeto desconhecido; outros, por não saberem mexer; outros, por terem vergonha de filmar e prejudicar a imagem por causa das mãos trêmulas (na grande maioria, em função de seqüelas do álcool). Mas quando entregamos/direcionamos a câmera de vídeo para eles - e, juntamente, manipulamos e experimentamos as primeiras cenas - ; poucos se negaram a usá-la. De acordo com Kastrup, quando introduzimos novas tecnologias cognitivas no cotidiano dos usuários e estes apresentam dificuldades e resistências, pode emergir aí a invenção de problemas, demonstrando a capacidade que os dispositivos técnicos tem de "[ . . . ] atuarem no processo de virtualização da inteligência e na alteração das formas de conhecer instituídas" (KASTRUP, 2000, p. 38).

Se, num primeiro momento, o novo (filmadora) se colocava como obstáculo, num segundo, a potencialidade de problematização levava à invenção de novas formas de conhecer, de novas regras de funcionamento cognitivo. Para Kastrup (2000), no momento em que o dispositivo se acopla à inteligência, esta é colocada num processo de virtualização, acionando processos de criação e de diferenciação em seu interior. Essa interface (zona de contato) homem - máquina opera, segundo a autora, no nível onde o atual guarda a dimensão virtual.

A filmadora proporciona outro tipo de contato e de comunicação, que desdobra as posições na rede de conversação, ao exigir daquele que usa a câmera ocupar o lugar de potencial entrevistador, enquadrar a imagem e decidir até quando vai a cena. Já, daquele que aparece na imagem, é exigido a tomada de uma posição enunciativa e de uma performance. Ambas as posições, possibilitam a criação e/ ou a invenção de um outro modo de ser e agir nesse coletivo. Aquele que filmava, ao agir como um entrevistador produzia outras coordenações de ações nessa rede de conversação, antes nada comuns. Geralmente, o participan- te que filmava fazia perguntas para aquele que estava sendo filmado, e essas perguntas, às vezes, levavam os sujeitos a pensarem sobre o personagem que estavam construindo e sobre eles próprios: Quem é que você está fazendo? Esse personagem é você? É você hoje ou você no passado? Quem você prefere? O que tu te identifica com esse personagem? Você gosta dele? Você ou o personagem tem algo a declarar?

O acoplamento filmadora-participante-entrevistador multiplica as modalidades enunciativas e suas posições: o entrevistador pode estar falando com o participante ou com o próprio personagem. Um sujeito equipado com uma filmadora é instigado a abrir facetas de visibilidade de quem é filmado, e, do mesmo modo, quem está sendo filmado pode-se colocar como participante, como personagem mascarado e/ou como personagem do próprio vídeo, ou todos eles.

Os extrovertidos faziam questão de aparecer na filmagem muito mais do que filmar. No entanto, quem se manifestava, com freqüência, para manipular a câmera eram as pessoas mais tímidas, que preferiam estar atrás da filmadora do que na frente dela. Esses ditos (considerados) tímidos, ao se acoplarem à filmadora, perdiam suas características de timidez e conseguiam interagir facilmente com os outros participantes. Se, antes, apareciam através de uma postura mais isolada na oficina, com o olhar focado na construção da máscara, agora, diante do acoplamento com a filmadora, ambos (máquina e humano) ganhavam lugar de ator nesse coletivo, o qual, segundo Lévy (1993) já não é mais puramente humano, uma vez que suas fronteiras estão em permanente redefinição.

Para Lévy, máquinas fotográficas e câmeras filmadoras não são apenas memórias, “[ . . . ] são também máquinas de perceber as sensações de outra pessoa, em outro momento e outro lugar [ . . . ]" (LÉVY, 1996, p. 28) e que estendem o alcance e transformam a natureza de nossas percepções. A filmadora virtualiza o olhar. O processo de virtualização não se opõe ao real (as coisas que persistem e resistem), mas se opõe ao atual, uma vez que a atualização aparece como solução de um problema.

Podemos pensar que a filmadora é um recurso de potencialização da oficina. Ao emergir como um ator na atividade, ela propicia um 
processo de virtualização (nó de forças) que leva à invenção de problemas.

A virtualização, passagem à problemática, deslocamento do ser para a questão, é algo que necessariamente põe em causa a identidade clássica, pensamento apoiado em definições, determinações, exclusões, inclusões e terceiros excluídos. Por isso a virtualização é sempre heterogênese, devir outro, processo de acolhimento da alteridade. (Lévy, 1996, p.25)

A resolução desses problemas pode-se dar na ordem do que é possível, do que é realizável, anulando o seu potencial inventivo, mas também pode ocorrer através da atualização (solução que não estava contida previamente no enunciado), que é a criação, a invenção de uma solução a partir da dinâmica de forças virtualizada no acontecimento. Segundo Lévy, se a virtualização for bloqueada, a alienação instala-se; se for cortada a atualização, as idéias, os fins, os problemas tornam-se bruscamente estéreis, incapazes de resultar na ação inventiva; se for impedida a realização, enfim, os processos perdem sua base, seu suporte, seu ponto de apoio, eles se desencarnam. "Todas as transformações são necessárias e complementares umas das outras." (LÉVY, 1996, p. 140-141)

Quando o vídeo era visto coletivamente (na semana seguinte à criação das máscaras), num primeiro momento, havia um silêncio. Segundo alguns participantes, esse silêncio era de estranhamento de sua própria imagem, de sua voz, de sua postura. Depois, vinham as risadas e os comentários sobre os personagens e as habilidades dos colegas. Surgiam comentários a respeito do corpo: Eu não tinha idéia de que eu estava com o rosto assim, eu envelheci. Que bom que eu engordei, quando cheguei aqui tava virado em osso, o crack deixa a gente chupado. É legal a gente se ver no vídeo, eu tô bem melhor do que eu era. O que eu acho muito estranho é minha voz, a aparência eu tô igual como eu sou. De acordo com Lévy, nesse momento em que todos vêem a produção coletiva na televisão, eles estão compartilhando o mesmo grande olho coletivo. "Graças às máquinas fotográficas, às câmeras e aos gravadores, podemos perceber as sensações de outra pessoa, em outro momento e outro lugar." (LÉVY, 1996, p. 28) Desta forma, o vídeo possibilita esse se ver de outro jeito em um coletivo. Além disso, é outro momento de troca e de apropriação deles, uma vez que, para outras pessoas assistirem, eles precisam dar autorização.
Um dos participantes, em uma das sessões de vídeo, mostrou-se perturbado ao ver-se na tela. Quando ele participou da oficina, havia acabado de ser transferido da unidade de desintoxicação para a unidade de tratamento e ainda estava um pouco confuso. Durante a atividade, falou o tempo inteiro, às vezes coordenando suas falas com as dos demais participantes, em outros momentos, suas falas eram dispersas, sobre assuntos diversos, sem direção, exigindo de alguns participantes, maior acolhimento, já que outros demonstravam rechaço. Sua voz era ouvida o tempo todo no vídeo.

Quando assistimos ao vídeo (nesse caso, foram duas semanas depois da atividade, por questões técnicas com a filmadora), esse paciente apresentava-se em outra situação. Ao se ver na tela, ele não se reconheceu: Eu não acredito que sou eu. Ele ficou em silêncio, paralisado, enquanto os outros participantes riam e brincavam com o que viam. Mas sua fala repetida - Não sou eu - fez com que todos silenciassem. Alguém perguntou: Por que tu acha que não é tu? Então, a resposta: Esse aí é insuportável, não cala a boca, só enche o saco, eu não estou assim, meu Deus, coitada da minha mãe, será que eu era assim em casa? Acho que pior, pois, quando desci da UD, eu já estava desintoxicando, em casa eu tô direto chapado, meu Deus, que criatura insuportável. A minha mãe dizia que eu ficava assim, mas sabe como é, né, a gente não acredita. Por que vocês não mandaram eu calar a boca? Os participantes tentaram acolher, explicando que isso pode acontecer com qualquer um e que muitos deles passaram pelo mesmo tipo de comportamento.

Esse participante, na visita familiar, procurou conversar com a mãe sobre o ocorrido. Nesse momento, ambos, com dificuldade, conseguiram falar sobre as implicações do uso de substâncias químicas na vida deles. Embora ainda com um ingrediente de culpa, nota-se que esse tipo de cognição ultrapassa a recognição estrita, ao potencializar a conversa com o familiar

O conteúdo do vídeo foi uma surpresa para todos, pois muitos filmaram a oficina, levando ao confronto diversas perspectivas, pontos de vistas e cenas. O que vemos na tela é o produto (atualização) de um coletivo que cumpre, ao mesmo tempo, duas funções: a de ser um contingente possibilitador das produções e a 
de reconhecer a singularidade das mesmas.

\section{Vídeo: dispositivo enativo}

Dubois (2004) acredita que o vídeo possa ser um dispositivo, um evento que envolve o expectador em relações, ao mesmo tempo perceptivas, físicas e ativas, abrangendo, portanto, muito mais do que as telas mostram, sendo possível “[ . . . ] pensar o vídeo como um estado e não como um produto, ou seja, como uma imagem que não pode ser desvinculada do dispositivo para o qual foi concedida" (MACHADO, 2004, p. 13). Podemos pensá-lo, então, como um dispositivo de grupalidade e de singularidade ao mesmo tempo.

Encarar o vídeo como estado, segundo Dubois (2004), implica acreditar que o mesmo seja uma experiência, uma maneira de ser e de viver as imagens mais do que um objetoimagem em si, já que ele pensa (ou permite pensar e sentir) o que as imagens são (ou fazem). De acordo com o autor, o vídeo pode ser compreendido como um ato mesmo do olhar, a expressão de uma ação.

[ ... ] vídeo é o ato de olhar se exercendo hic et nunc, por um sujeito em ação. Isto implica ao mesmo tempo uma ação em curso (um processo), um agente operando (um sujeito) e uma adequação temporal ao presente histórico: 'eu vejo' é algo que se faz 'ao vivo' [ . . . ] (DUBOIS, 2004, p. 72)

A proposição do autor permite compreender que o vídeo possibilita atualizar, no campo da experiência, a enação em estado de ato, acontecendo. Assim, o ato de filmar produz uma duração em ato, a experiência de um gerúndio. A ação de filmar a oficina e a experiência de retomar esse vídeo constituem-se num dispositivo de atualização enativa. É por essa operação de duração do tempo gerúndio, do acontecendo, que podemos dizer que se desdobra aí um virtual inusitado à rede de conversação estabelecida institucionalmente. O vídeo não existe somente como registro da experiência, mas como desdobramento de criação, como um modo distinto de linguajar, ou seja, de realizar coordenações de ações recursivas e inusitadas e não somente consensuais.

Podemos ainda agregar que a convergên- cia de diversas formas de linguajar, propostas na oficina (oral, gestual, gráfica, fotográfica, videográfica), amplia o repertório de coordenações de ações recorrentes, possibilitando a emergência de outras convergências e de outros emocionares não oportunizados pelas demais redes de conversação instituídas no serviço. Segundo Maturana (1999), a linguagem é um processo que se dá no espaço de coordenações consensuais de conduta, que se constituem no fluir dos encontros corporais recorrentes. As palavras, os gestos, os grafismos, a fotografia e o vídeo são operações nos domínios da existência, de tal modo que o fluir de mudanças corporais, posturas e emoções se relaciona com o conteúdo do linguajar. Dessa forma, linguajar e emocionar entrelaçam-se numa modulação contínua, como resultado da convivência.

A rede de conversação produzida na oficina de máscaras era atualizada no momento em que assistiam ao vídeo, mas também em outros, como pelo transbordar desse conversar com familiares e profissionais no cotidiano da instituição. Nos encontros familiares, o assunto não era apenas relativo ao tratamento, à aceitação da condição de doente e tudo o que isso acarreta. Contar sobre a oficina, o vídeo e as questões que daí emerge tornou-se possível como outra rede de conversação familiar, baseada menos na culpa e mais em uma produção. O mesmo ocorreu com os profissionais da instituição que não vivenciaram a atividade. Os participantes, ao contarem a sua experiência, relatavam outras facetas de si mesmos, ampliando as concepções que os trabalhadores tinham dos próprios internos.

O trabalho também nos instiga a pensar que a potência de colocar questões pertinentes a um coletivo que assim as caracteriza - que aqui qualificamos como uma das facetas de uma cognição enativa - pode-se constituir em um dispositivo de criação para sujeitos que, por suas circunstâncias, se encontram vivendo experiências de sofrimento. Talvez, ao invés de somente tentar ajudá-los a solucionar os problemas, devamos também oportunizar que formulem e aceitem como pertinentes suas questões. 


\section{Referências}

AXT, M.; MARASCHIN, C. Conhecimento. In: JACQUES, M.; STREY, M.; BERNARDES, N.; GUARESCHI, P.; CARLOS, S.; FONSECA, T. Psicologia Social Contemporânea. Petrópolis: Ed. Vozes, 1998. p133-145.

CAPELLA, N.; MARASCHIN, C.; MAURENTE, V.S.; RICKES, S. Tecnologias Digitais e Jovens Usuários de Serviço de Saúde Mental. Informática na Educação: teoria e prática, Porto Alegre, v. 11, n. 1, p. 79-90, jan./jun. 2009.

COSTA, C.; FIGUEIREDO, A. (Org.). Oficinas Terapêuticas em Saúde Mental: sujeito, produção e cidadania. Rio de Janeiro: Contra capa Livr., 2004.

DIEHL, R.; MARASCHIN, C.; TITTONI, J. Planografias em Pesquisa: mapas e fotografias na saúde mental. Interface: comuicação, saúde, educação, São Paulo, 2009. Disponível em: <http://www.scielo.br/scielo. php?script=sci_arttext\&pid=S1414-32832009000300008\&lng=e\&nrm=iso\&tlng=e> Acessado em: 10 jul. 2009.

DUBOIS, P. Cinema, Vídeo, Godard. São Paulo: Cosac Naify, 2004.

FRANCISCO, D.J.; MARASCHIN, C.; AXT, M. Informática e Saúde Mental: caminhos de uma oficina. RENOTE: Revista Novas Tecnologias na Educação, Porto Alegre, v. 5, p. 1-16, 2007.

KASTRUP, V. A Invenção de Si e do Mundo: uma introdução do tempo e do coletivo no estudo da cognição. Campinas: Papirus, 1999

KASTRUP,V. Novas Tecnologias Cognitivas: o obstáculo e a invenção. In: PELLANDA, N.; PELLANDA, E. (Org.). Ciberespaço: um hipertexto com Pierre Lévy. Porto Alegre: Artes e Ofícios, 2000. p. 38-54.

LÉVY, P. As Tecnologias da Inteligência. Rio de Janeiro: Ed. 34, 1993.

LÉVY, P. O que é o Virtual? São Paulo: Ed. 34, 1996.

LÉVY, P. A Inteligência Coletiva. São Paulo: Loyola, 1998.

MACHADO. A. Apresentação. In: DUBOIS, P. Cinema, Vídeo, Godard. São Paulo: Cosac Naify, 2004. p11-20.

MATURANA, H. A Ontologia da Realidade. Belo Horizonte: Ed. UFMG, 1999.

MATURANA, H. Cognição, Ciência e Vida Cotidiana. Belo Horizonte: Ed. UFMG, 2001.

MATURANA, H.; VARELA, F. A Árvore do Conhecimento: as bases biológicas da compreensão humana. São PauIo: Palas Athena, 2001.

RAINONE, F.N.; FROEMMING, L.S. As Potencialidades das Imagens Cinematográficas Para o Campo da Atenção em Saúde Mental. Latin American J ournal of Fundamental Psychopathology on Line, São Paulo, v. 5, p. 69-83, 2008.

VARELA, F.; THOMPSON, E.; ROSCH, E. A Mente Incorporada: ciências cognitivas e experiência humana. Porto Alegre: Artmed, 2003.

VIANNA, T. R. Oficinando Enredos de Passagem: o encontro do adolescer em sofrimento com a tecnologia. 2008. Dissertação (mestrado) - Universidade Federal do Rio Grande do Sul, 2008, Porto Alegre, BR-RS. 
SANTORUM, K. Pelas Fendas do Trabalho Vivo: textos, contextos e atos na atividade de Vigilância em Saúde do Trabalhador. 2006. Tese (Doutorado) - Escola Nacional de Saúde Pública Sérgio Arouca (ENSP), Fundação Oswaldo Cruz (FIOCRUZ), Rio de Janeiro: 2006.

Recebido em agosto de 2009

Aprovado para publicação em dezembro de 2009

\section{Graziela Pereira Lopes}

Psicóloga, Mestre em Psicologia Social e Institucional (UFRGS)

E-mail: grazilopes@hotmail.com

\section{Cleci Maraschin}

Professora do Instituto de Psicologia da Universidade Federal do Rio Grande do Sul E-mail: cleci.maraschin@ ufrgs. 